\title{
Economic and Environmental Impact Trade-Offs Related to In-Water Hull Cleanings of Merchant Vessels
}

Pagoropoulos, Aris; Kjær, Louise Laumann; Dong, Yan; Birkved, Morten; McAloone, Tim C.

Published in:

Journal of Industrial Ecology

Link to article, DOI:

10.1111/jiec. 12627

Publication date:

2018

Document Version

Peer reviewed version

Link back to DTU Orbit

Citation (APA):

Pagoropoulos, A., Kjær, L. L., Dong, Y., Birkved, M., \& McAloone, T. C. (2018). Economic and Environmental Impact Trade-Offs Related to In-Water Hull Cleanings of Merchant Vessels. Journal of Industrial Ecology, 22(4), 916-929. https://doi.org/10.1111/jiec.12627

\section{General rights}

Copyright and moral rights for the publications made accessible in the public portal are retained by the authors and/or other copyright owners and it is a condition of accessing publications that users recognise and abide by the legal requirements associated with these rights.

- Users may download and print one copy of any publication from the public portal for the purpose of private study or research.

- You may not further distribute the material or use it for any profit-making activity or commercial gain

- You may freely distribute the URL identifying the publication in the public portal 


\title{
Economic and environmental impact trade-offs related to in-water hull cleanings of merchant vessels
}

The case of tanker vessels

Aris Pagoropoulos ${ }^{a}$, Louise Laumann Kjaer ${ }^{a}$, Yan Dong ${ }^{b}$, Morten Birkved ${ }^{b}$, Tim C. McAloone ${ }^{a}$

${ }^{a}$ Technical University of Denmark, Department of Mechanical Engineering

${ }^{\mathrm{b}}$ Technical University of Denmark, Department of Management Engineering

\begin{abstract}
Merchant vessels are equipped with antifouling systems to prevent accumulation of marine organisms on the hull - a phenomenon known as fouling. In many cases however, fouling accumulates and in-water hull cleaning is required. Hull cleanings are part of a hull management scheme, and although they are an established practice, their associated environmental and economic trade-offs and conflicts have remained largely unexplored.
\end{abstract}

The purpose of this article is to quantitatively assess both economic and environmental impacts of hull management schemes on the operation of tanker vessels. After identifying induced and avoided costs and environmental impacts from the hull management system, we used both temporally and spatially distributed models to capture the degradation of the antifouling system as well as the global sailing profile of the vessels. Lastly, we analyzed how each of the modelled impacts varied with the frequency of hull cleanings within the hull management scheme.

Our analysis revealed a convex relationship between the frequency of hull cleanings and fuel savings. The higher the frequency of hull cleanings, the less fuel savings can be achieved per cleaning. In terms of costs, from some point on the costs of the service are likely to offset the savings-especially if fuel prices are low. In regards to climate change, avoided emissions due to fuel savings are likely to outweigh the limited 
impacts from the service itself. Lastly, while ecosystem impacts from marine, terrestrial and freshwater ecotoxicity are likely to increase from hull cleanings, they are subject to high uncertainties.

Keywords: Life cycle management, fuel efficiency, Shipping, Antifouling systems, Product-Service Systems

\section{About the authors}

Aris Pagoropoulos is a Ph.D. candidate at the Technical University of Denmark in Kongens Lyngby, Denmark.

Louise Laumann Kjaer is a Ph.D. candidate at the Technical University of Denmark in Kongens Lyngby, Denmark.

Yan Dong is a postdoc at the Technical University of Denmark in Kongens Lyngby, Denmark.

Morten Birkved is an associate professor at the Technical University of Denmark in Kongens Lyngby, Denmark.

Tim C. McAloone is a professor at the Technical University of Denmark in Kongens Lyngby, Denmark.

\section{Address correspondence to:}

Aris Pagoropoulos, Department of Mechanical Engineering, Technical University of Denmark, Producktionstorvet, Building 426, Kongens Lyngby, Denmark. Email: aris.pagoropoulos@gmail.com

\section{Introduction}

\section{Description of a hull management scheme and the role of hull cleanings}

During the operation of merchant vessels such as tankers and container ships, a part of the hull is continuously immersed in water, and therefore numerous marine organisms accumulate on it (Almeida, Diamantino, and de Sousa 2007). This undesirable accumulation of microorganisms, plants, and animals is termed marine biofouling (Yebra, Kiil, and Dam-Johansen 2004), and results in increased fuel consumption 
due to generated roughness, increased corrosion of the hull, and higher maintenance costs (Cao et al. 2010). To battle this phenomenon, vessels are equipped with antifouling systems. Nevertheless, aggressive fouling might attach on the hull due to high fouling pressure especially in warm waters (Tribou and Swain 2015), or when the vessel is sailing slow (Yebra, Kiil, and Dam-Johansen 2004) (figure 1a). In water hull cleanings (hereafter called hull cleanings) can mitigate the effects of fouling. During hull cleanings, a team of divers removes marine organisms such as algae, crustaceans and slime that have settled on the hull using brush carts (figure $1 \mathrm{~b}$ ). The result of the service is a cleaned hull, as shown in figure $1 \mathrm{c}$.

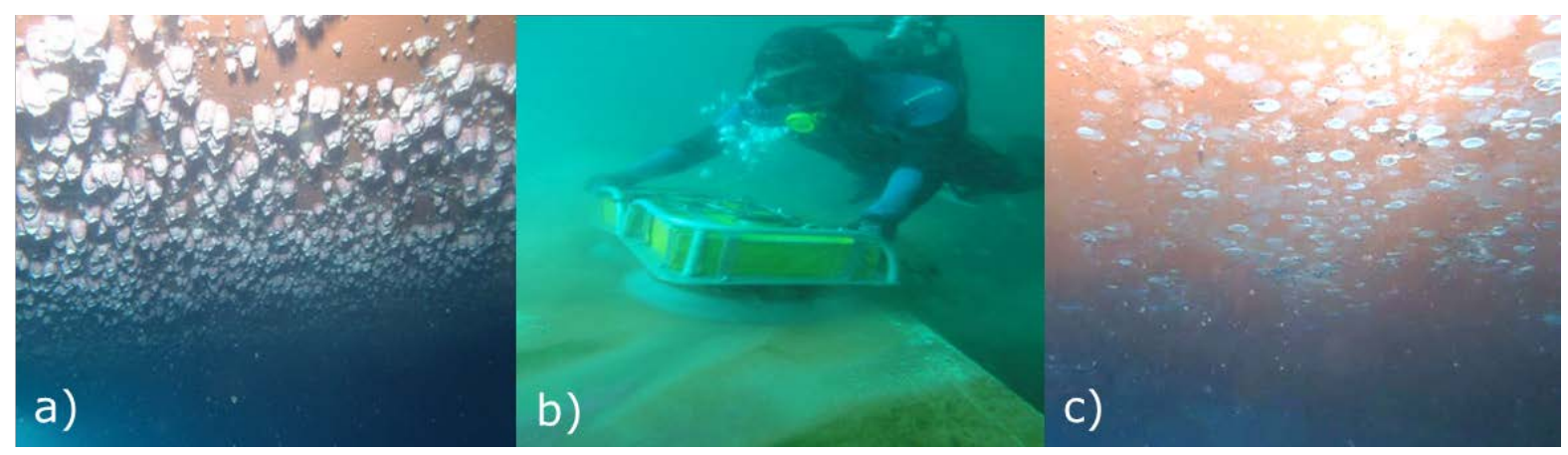

Figure 1: a) Marine fouling on the flat bottom of a tanker vessel b) Diver cleaning the hull using a portable brush cart c) Flat bottom after hull cleaning

Hull cleanings are part of a hull management scheme, whose overall aim is to mitigate increased costs due to higher frictional drag from fouling. At the same time though, environmental and economic trade- offs associated with the management schemes have remained largely unexplored and possible conflict between cost and different environmental impacts are not clearly understood. Previous Life Cycle Assessments (LCAs) (Blanco-Davis and Zhou 2014; Blanco-Davis, del Castillo, and Zhou 2014) highlight the benefits of antifouling systems with particular focus on the application of the paint in dry dock. Nevertheless, these studies do not challenge the degradation of fouling protection and the need for maintenance in the form of hull cleanings during the operation of the vessel.

\section{Methodology}


This study investigates the impacts from a specific functional outcome (i.e. a clean hull), delivered through a specific service (i.e. the hull management scheme). Life Cycle Assessment (LCA) and Life Cycle Costing (LCC) methodologies are employed to assess environmental and cost impacts respectively. While LCA in principle does differentiate between tangible products \& intangible services, the product-centric nature of LCA is nevertheless evident (Kjaer et al. 2016). When assessing the environmental performance of a Product-Service System like the hull management scheme, it is important that the assessment takes into account how the impacts of the reference system are affected by the service as well as ensuring that the direct and indirect impacts from the service itself are captured (Kjaer et al. 2016). In the case presented in this article, the reference system is the operation of the vessels and the service is the hull cleaning service. The hull management scheme will influence the operational efficiency of the ship, resulting in avoided impacts through system expansion, while the hull cleaning service will result in induced impacts. The assessment of the costs and environmental impacts of a hull management scheme was thus performed in three steps:

Step 1: Identifying avoided and induced costs and environmental impacts.

Initially, we identified which processes were changed as a result of hull cleaning service. The costs and environmental impacts stemming from these processes were categorized as either leading to avoided or induced impacts. Replaced or reduced processes lead to avoided impacts by means of system expansion, as they result in avoided impacts in the reference system. Added processes from the hull cleaning service were categorized as induced impacts. Based on the nature of the identified processes and existing literature, we identified the relevant environmental impact categories in the impact assessment. Also, identified impacts that could not be assessed quantitatively are only discussed qualitatively.

\section{Step 2: Modelling approach}

For each of the chosen impact categories, the modelling approach was determined, including both the relevant inventory data and the assessment method. The study relied on multiple data sources, including 
expert opinions and personal correspondences. A list of the data sources are shown in the Table S1 in the Supporting information.

Step 3: Analysis of a hull management scheme

Lastly, it was analyzed how each of the modelled impact potentials vary with the frequency of hull cleanings. The purpose of this step was to conclude if any recommendations for the optimal hull management scheme could be identified and in order to reveal potential trade-offs between impact categories. This analysis step also included a sensitivity analysis.

\section{Case study description}

\section{Antifouling systems}

Paint systems that prevent fouling have important benefits for shipping, as discussed in (Blanco-Davis, del Castillo, and Zhou 2014; Munk, Kane, and Yebra 2009; M. P. Schultz et al. 2011). The first such systems appeared in the mid-19th century and delivered protection from fouling through emission of toxic ingredients such as copper, arsenic or mercury oxide, dispersed in linseed oil, shellac or rosin (Almeida, Diamantino, and de Sousa 2007; Lunn 1974). Ever since, antifouling technology has evolved substantially. From the 1st of January 2003 tributyltin (TBT)-based paints have been banned due to their adverse effect on the environment (Yebra, Kiil, and Dam-Johansen 2004; Evans, Birchenough, and Brancato 2000; International Maritime Organization 2009). Since then new paint systems have been developed (see (Lindholdt et al. 2015) for a recent review of various commercially available technologies).

The two main technologies commercially available today are biocidal antifouling paints and fouling release paints (Lindholdt et al. 2015). Focus in this article is on biocidal antifouling paints (hereafter referred to as antifouling paint). Antifouling paint is a combination of two basic components (Yebra, Kiil, and DamJohansen 2004; Almeida, Diamantino, and de Sousa 2007; Goldschmidt and Streitberger 2003; Interlux 
2012): the first is the binder, which holds the product together, forms the coating film and controls the release of the active ingredients. The second is the active ingredients, essentially a mix of biocides that repel fouling. The most common types of biocides are copper compounds such as cuprous oxide or metallic copper and a mix of booster biocides such as Igrarol, Diuron, Chlorothalonil, Dichlofluanid, Kathon, TCMTB, Zinc Pyrithione and Zineb (N. Voulvoulis, Scrimshaw, and Lester 1999; Nikolaos Voulvoulis 2006). Aside from the paint, the antifouling system of the vessel is also complimented by passive cathodic systems, such as zinc anodes and Immersed Current Cathodic Protection (ICCP) systems that also prevent corrosion. The effect and efficacy of those systems is outside of the scope of this study (see Gratsos \& Zachariadis, (2007) for more information).

Antifouling systems need to meet multiple requirements (Chambers et al. 2006; Lindholdt et al. 2015) such as the ability to prevent -or at least limit- biofouling regardless of a ship's operating profile, environmental soundness, economic viability, longevity, strong adhesion with the underlying coating, mechanical strength, long-term durability and low drag, while targeting only species that can attach to ship hulls. The fouling process -and consequently the effectiveness of the paint- is influenced by multiple factors such as sun light, water temperature, oxygen concentration in the water, the existence of mineral nutrients, water salinity, and vessel speed (International 2010; Kiil et al. 2002; Almeida, Diamantino, and de Sousa 2007).For merchant vessels, antifouling paint has a lifetime normally of five years, after which the vessel needs to be repainted in dry dock.

\section{Hull cleaning description}

Despite the continuous development of antifouling technologies, fouling often occurs and the hull requires cleaning to maintain a smooth, fouling-free surface (Schiff, Diehl, and Valkirs 2004; Earley et al. 2014). For merchant vessels of considerable size, where frequent dry dockings are impractical, in-water hull cleaning is the most common method (Armstrong 2013). During hull cleaning, a group of divers equipped with brush carts sweep the hull to remove hard fouling. The demand for cleaning is not constant throughout the life 
cycle of the antifouling paint, and is likely to increases as the time progresses due to degrading coating efficacy (Earley et al. 2014). In regards to the timing of hull cleanings, it is preferable to clean before bigger fouling organisms attach to the hull, as in this case very soft brushes can be used, and the antifouling paint is not likely to be damaged (Munk, Kane, and Yebra 2009).

The global regulatory framework in the maritime industry provides little guidance on how or when to perform hull cleanings. Hull cleanings are optional in the sense that shipowners are neither prevented, nor required to manage the condition of the hull. For example, the "Guidelines for inspection of anti-fouling systems on ships" from the International Maritime Organization (International Maritime Organization 2003), focus exclusively on the chemical composition of the antifouling paint, while the existence and the extent of marine fouling is not even being mentioned. Overall, there is a lack of uniformity between different countries with regards to the regulatory framework around hull cleanings. For example, environmental rules forbid hull cleanings in ports in South Africa, and allow the service to be carried only in off-port limit anchorages, provided that they comply with South African Maritime Association's rules and regulations (Inchcape 2016). In United Arab Emirates (UAE) and Singapore on the other hand, hull cleaning is permitted in the port anchorage area (Fujairah port authority 2016; Maritime and port authority of Singapore 2008). Some governments provide best practice guidance on hull cleanings. For example, the Australian Department of Agriculture, Fisheries and Forestry suggests hull cleanings every 6-12 months (Australian Government 2012, p.11).

In practice, hull cleanings are conducted mainly based on commercial considerations, as it is entirely up to the shipowner to decide when and where to perform a hull cleaning. In some cases, shipowners can be legally obliged to do so by the owners of the cargo (see for example the Hull Fouling Clause for Time Charter Parties in (BIMCO 2013) or the manual for SIRE inspections in (Oil Companies International Marine Forum 2016, p. 156, paragraph 12.1)). Moreover, economic realities such as the substantial price 
discrepancies in hull cleaning service among different countries and the existence of key ports means that hull cleanings are mostly conducted in a limited amount of ports.

\section{Goal and scope of the study}

The goal of this study is to quantitatively assess the economic \& environmental impacts of a hull management scheme, as identified in the previous section, while taking into account the uncertainty associated with such an assessment. As the amount of hull cleanings delivered within the management scheme is likely to vary depending on their economic and environmental benefits, the goal is to understand how the economic \& environmental impacts are influenced by the frequency of hull cleanings. The target audience for this study is decision makers working with the technical management of vessels. The functional unit is defined as the delivery of a hull management scheme on a Medium Range tanker vessel throughout the five year life cycle of the paint, and the reference flow is the amount of hull cleanings delivered in that period. Hull management schemes were assessed for a group of Medium Range tanker vessels, with similar operation patterns and where the same type of paint has been applied. The type of paint under study was based on self-polishing antifouling technology. It combines self-polishing copolymer (SPC) acrylic polymers with a certain amount of rosin. The paint undergoes a reaction with sea water to make it soluble. During the reaction water migrates into the paint film and dissolves rosin and biocides which then leach into the sea (International 2010; Yebra, Kiil, and Dam-Johansen 2004).

Analysis was performed under the assumption of constant speed. In tramp shipping, ships have to sail at a specific speed called charter party speed that is stipulated in the charter party contract between the owner of the cargo and the shipowner. The legal requirement to sail at the charter party speed with an error margin of plus/minus half a knot effectively means that, irrespective of the condition of the hull, the vessels 
are sailing at constant speed on average (Maynes 1998). Table 1 lists the characteristics of the vessels under study, together with the baseline assumptions for the analysis

Table 1: Characteristics of vessels under study and study assumptions.

\begin{tabular}{|l|l|}
\hline Vessel type & Product carriers, carrying petroleum distillates such as Naptha, \\
\hline Number of vessels considered in the & oils \\
\hline study & 20 \\
\hline Vessel deadweight tonnage & \\
\hline Vessel design speed & Between 37000 and 47000 DWT \\
\hline Charter party speed & 15.5 knots \\
\hline Period of evaluation & 13 knots \\
\hline Fuel consumption at charter party speed & 23 metric tons of fuel/ 24 hours \\
\hline Sailing frequency & From $06 / 2012$ to $01 / 2015$, covering a total of 47 vessel years, \\
\hline Average vessel building date & 208 days per year \\
\hline Average area of the submerged part of & 9247 m $^{2}$ \\
\hline
\end{tabular}

\section{Environmental impacts and costs from hull management schemes}

The environmental impacts and costs from the hull management scheme are shown in the flow diagram in figure 2. Notice that in order to describe the impacts associated with a hull management scheme, the avoided impacts in the operational of the vessel during the five-year lifetime of the antifouling system and 
the induced impacts from the hull cleaning service were identified and included within the system boundaries.

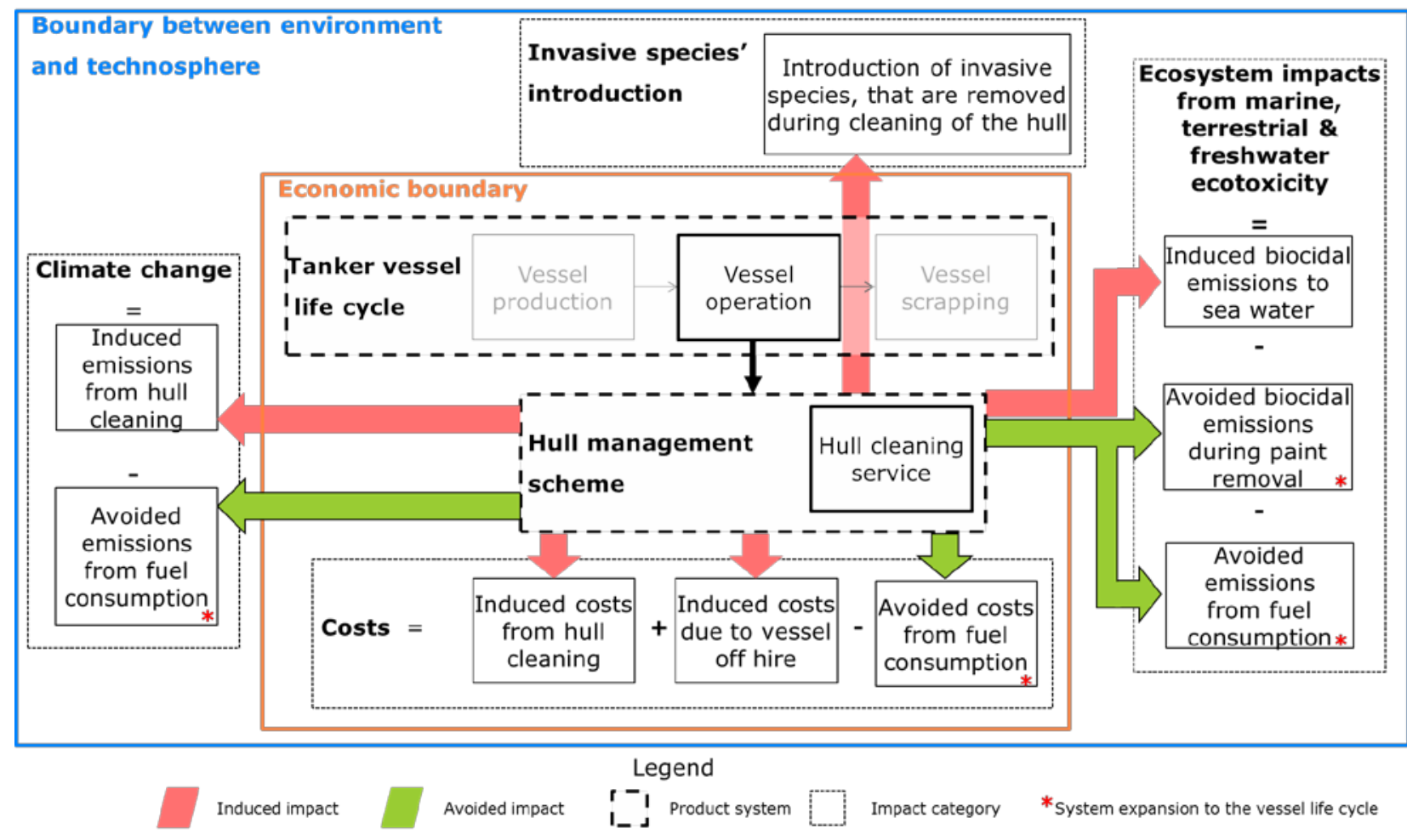

Figure 2: Flow diagram for the hull management scheme and its associated impacts.

Shipping contributes to a number of environmental impacts (The Danish Shipowners' Association 2012), most of which are being addressed through various regulations from the International Maritime Organisation (IMO) (United Nations Conference on Trade and Development 2013). Through a literature review we identified that hull management schemes primarily influence three of those impacts: climate change, ecosystem impacts from marine, terrestrial \& freshwater ecotoxicity, and introduction of invasive species.

For shipping, greenhouse gas (GHG) emissions account for approximately $3.1 \%$ of global emissions contributing to climate change (Smith et al. 2014). And in regards to legislation from other environmental 
impacts from shipping, climate change can be considered the least regulated area (Kjær et al. 2015). Hull cleanings result in avoided fuel consumption, which in turn lead to reduced emissions of greenhouse gases. On the other hand, hull cleanings entail emissions associated with the delivery of the service itself.

Emissions of active compounds and avoided fuel emissions lead to ecosystem impacts from marine, terrestrial \& freshwater ecotoxicity. Fuel emissions from diesel engines contain organic elements, ions and a variety of particulate and semi-volatile organic compounds, all of which have toxicity impacts (Zielinska et al. 2004). Hull cleanings can result in short term increase of continuous dissolution of active compounds during subsequent environmental exposure (Earley et al. 2014; Valkirs et al. 2003).

Hull cleanings, especially when not conducted properly or in cases where hard fouling necessitates the use of steel brushes, can lead to in-water paint removal. And since paint is completely removed after five years in dry dock, when the hull is blasted and the vessel is repainted, hull cleanings effectively shift emissions from the paint removal to the operation of the vessel. Furthermore, the impact of those emissions depends on the hull treatment during dry dock. If the hull is hydroblasted, chemical precipitation of wastewater is possible by addition of iron or aluminum sulphate, in which case the copper is recovered in the form of copper sulphide (Choi, Kim, and Lim 2006). Copper sulphide can be used as an absorption coating material for catalysis and photovoltaics (Sartale and Lokhande 2000), so the precipitation process avoids emissions during copper sulphide production. It should be noted however, that during hydroblasting there is always a risk that wastewater will leak into the sea (The BAT group 1996; International Maritime Organization 2009). In cases where the hull is sandblasted, the removed paint can get mixed with the sand. And since the sand is often not recycled, copper will eventually end up either in the ground or into the sea (The BAT group 1996).

The last important environmental impact from hull cleanings is the introduction of invasive species. For shipping it is a major area of concern, as vessels are largely responsible for introduction of invasive species, both through ballast water discharge (Ruiz et al. 1997), but also due to construction and expansion of 
artificial waterways such as the Suez Canal (The Economist 2015). At the same time, hull cleanings are not an adequate preventive measure. In 2005 the ministry of fisheries in New Zealand ordered a report to assess the risk of hull cleaning activities (Woods et al. 2005). The report concluded that in water hull cleaning cannot adequately prevent invasive species introduction, as physical removal of fouling assemblages from vessel hulls does not result in mortality of all organisms. Hanafiah et al. (2013) also identified hull fouling as one cause effect pathway for introduction of invasive species via shipping-related transport. Therefore, invasive species is also considered an environmental impact affected by hull cleanings - potentially of considerable proportions.

In terms of avoided costs, hull cleanings reduce the drag of the hull and avoid extra fuel consumption. In terms of induced costs, hull cleanings incur not only the cost of the service itself, but also off hire costs as the vessel cannot trade while the vessel is cleaned.

Lastly, other environmental impacts from the hull cleaning service are not considered as they did not appear during literature review. Nevertheless given the focus on the operation of tanker vessels, the environmental impacts of the hull management scheme that are not covered in this study are likely due to be driven by the combustion of fossil fuels. This is especially true for transportation services as - with the exception of toxicity to ecosystems and humans, depletion of resources, and land use- other environmental impacts show a good correlation with climate change (Laurent, Olsen, and Hauschild 2012).

\section{Modelling approach}

In regards to the quantitative part of the assessment, table 2 lists the affected impact categories, the associated processes, together with a small description of the modelling approach and characterization methods that were employed in this study. Figure 3 shows the Causal Loop Diagram for the hull management system in order to visualize the connections between the variables that were used in this study (Laurenti et al. 2014). 


\begin{tabular}{|c|c|c|c|}
\hline $\begin{array}{l}\text { Impact } \\
\text { category }\end{array}$ & Processes & Modelling approach & Characterization method \\
\hline \multirow[t]{2}{*}{ Costs } & $\begin{array}{l}\text { Induced and avoided costs } \\
\text { from the service and due to } \\
\text { vessel off hire }\end{array}$ & $\begin{array}{l}\text { Service and off hire costs } \\
\text { based on financial \& } \\
\text { operational data }\end{array}$ & - \\
\hline & $\begin{array}{l}\text { Avoided costs from } \\
\text { decreased fuel } \\
\text { consumption }\end{array}$ & $\begin{array}{l}\text { Fuel consumption based on } \\
\text { regression model, that } \\
\text { describes the development of } \\
\text { fuel penalty throughout the } \\
\text { life cycle }\end{array}$ & - \\
\hline \multirow[t]{2}{*}{$\begin{array}{l}\text { Climate } \\
\text { change }\end{array}$} & $\begin{array}{l}\text { Induced and avoided } \\
\text { greenhouse gas emissions } \\
\text { from the service }\end{array}$ & $\begin{array}{l}\text { Calculation based on vessel } \\
\text { operational data and data } \\
\text { from hull cleaning companies. } \\
\text { Associated upstream impacts } \\
\text { are calculated based on data } \\
\text { from a hybrid Environmental } \\
\text { Input /Output (EIO) database } \\
\text { (FORWAST 2014) }\end{array}$ & $\begin{array}{l}\text { Characterization using IPCC } \\
\text { equivalence factors (Forster et } \\
\text { al. 2007) }\end{array}$ \\
\hline & $\begin{array}{l}\text { Avoided greenhouse gas } \\
\text { emissions from decreased } \\
\text { fuel consumption }\end{array}$ & $\begin{array}{l}\text { Fuel consumption based on } \\
\text { regression model that } \\
\text { describes the development of } \\
\text { fuel penalty throughout the } \\
\text { life cycle. Direct emissions }\end{array}$ & $\begin{array}{l}\text { Characterization using IPCC } \\
\text { equivalence factors (Forster et } \\
\text { al. 2007) }\end{array}$ \\
\hline
\end{tabular}




\begin{tabular}{|c|c|c|c|}
\hline & & $\begin{array}{l}\text { from fuel combustion is } \\
\text { modelled using primary data, } \\
\text { while upstream impacts from } \\
\text { fuel production are calculated } \\
\text { based on data from a hybrid } \\
\text { input output database } \\
\text { (FORWAST 2014) }\end{array}$ & \\
\hline \multirow[t]{2}{*}{ Ecotoxicity } & $\begin{array}{l}\text { Induced biocidal emissions } \\
\text { to sea water }\end{array}$ & $\begin{array}{l}\text { Calculation based on } \\
\text { estimated copper leach rate } \\
\text { for ablative paints from } \\
\text { (Earley et al. 2014). }\end{array}$ & $\begin{array}{l}\text { Use of spatially differentiated } \\
\text { ecotoxicity characterization } \\
\text { factors from (Dong, } \\
\text { Rosenbaum, and Hauschild } \\
\text { 2016). Booster biocides not } \\
\text { assessed due to uncertainties in } \\
\text { inventory and lack of } \\
\text { characterization factors. }\end{array}$ \\
\hline & $\begin{array}{l}\text { Avoided biocidal emissions } \\
\text { to soil during paint removal }\end{array}$ & $\begin{array}{l}\text { Calculation based on mass } \\
\text { balancing of copper emissions. }\end{array}$ & $\begin{array}{l}\text { Use of characterization factors } \\
\text { from (Owsianiak et al. 2013) for } \\
\text { terrestrial ecotoxicity and } \\
\text { (Dong, Rosenbaum, and } \\
\text { Hauschild 2016) for marine } \\
\text { ecotoxicological impact } \\
\text { potential . Booster biocides not } \\
\text { assessed due to uncertainties in } \\
\text { inventory and lack of }\end{array}$ \\
\hline
\end{tabular}




\begin{tabular}{|c|c|c|c|}
\hline & & & characterization factors. \\
\hline & $\begin{array}{l}\text { Avoided toxic emissions } \\
\text { from fuel consumption }\end{array}$ & $\begin{array}{l}\text { Calculation based on a } \\
\text { regression model that } \\
\text { describes the development of } \\
\text { fouling throughout the life } \\
\text { cycle. }\end{array}$ & $\begin{array}{l}\text { Characterization of ecotoxicity } \\
\text { impacts using USETox } \\
\text { (Rosenbaum et al. 2008) }\end{array}$ \\
\hline $\begin{array}{l}\text { Invasive } \\
\text { species }\end{array}$ & $\begin{array}{l}\text { Introduction of invasive } \\
\text { species, that are removed } \\
\text { from the hull during } \\
\text { cleaning }\end{array}$ & $\begin{array}{l}\text { Missing from LCA and } \\
\text { therefore not assessed } \\
\text { (Curran et al. 2011) }\end{array}$ & - \\
\hline
\end{tabular}




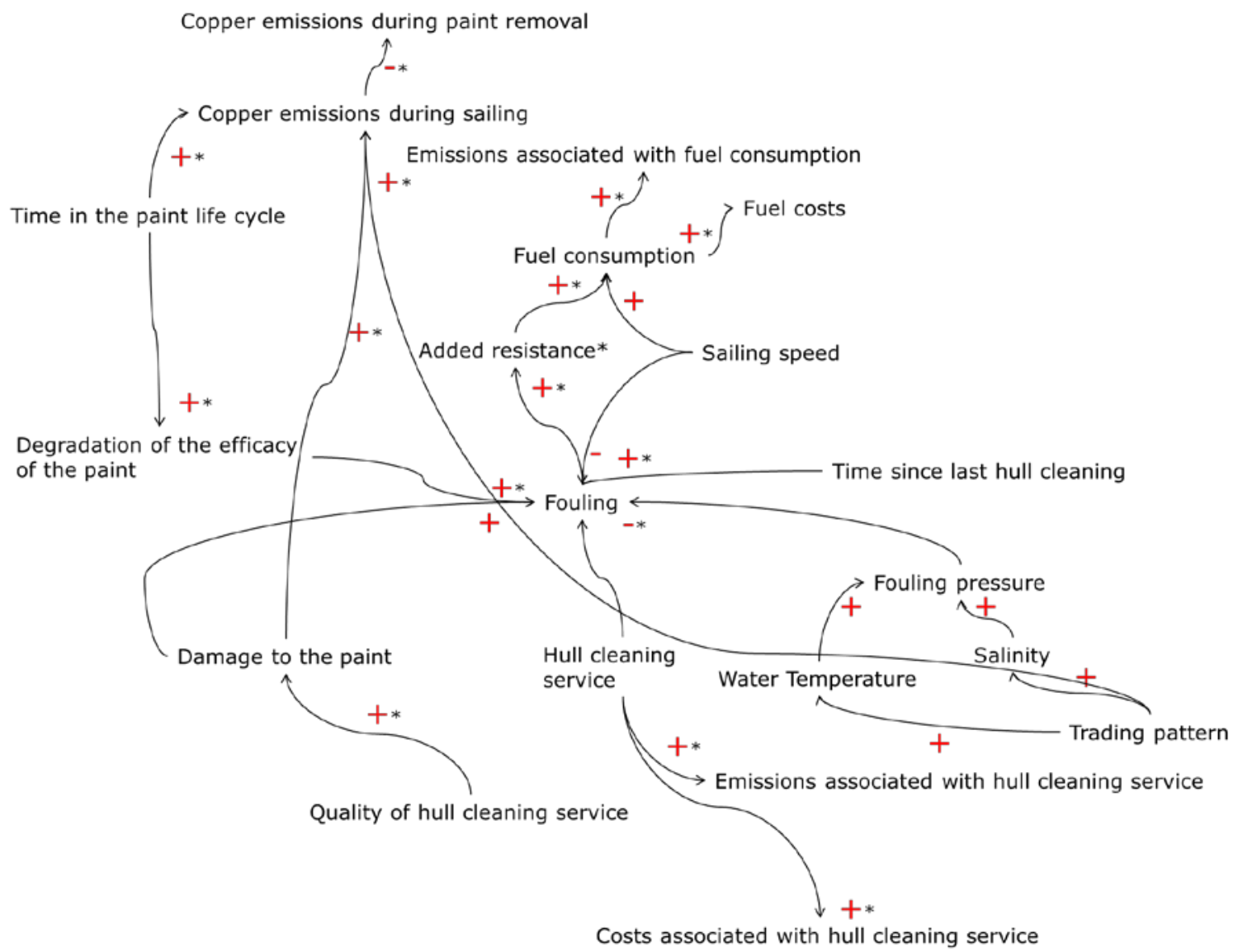

Figure 3: Causal Loop Diagram (CLD) of the hull management system. The causal links marked with an asterisk (*) represent causal relationships that were modelled in the study (see also Table 2)

From the main environmental impact categories covered by our work and as presented in table 2, invasive species are not assessable. Although studies have tried to develop methodologies to evaluate the effect of invasive species to eco-systems (see for example (Hanafiah et al. 2013)), invasive species as a assessable impact pathway and hence as an impact category is missing from LCA (Curran et al. 2011).

As discussed earlier, marine and terrestrial ecotoxicity impacts from hull cleanings are caused by emissions of cuprous oxides and booster biocides from the antifouling paint. For marine ecosystems, metals are at the top of toxicity concerns (Dong, Rosenbaum, and Hauschild 2016), which misaligns with the fact that copper oxides are the primary active ingredient in the hull paint that prevents fouling (Earley et al. 2014). As copper forms insoluble complexes in sea water effectively binding the copper thereby reducing the 
bioavailability of copper emissions (Voulvoulis, Scrimshaw, and Lester 1999), only impacts from dissolved copper are assessed in this study.

Booster biocides in antifouling paints are highly toxic (Yebra, Kiil, and Dam-Johansen 2004) as these compounds have been designed to have high biological activity. And as a result of legislation, their use and corresponding concentrations are restricted (Erich and Baukh 2016). In this study, quantitative assessment of the booster biocides is omitted. The main reason is that there is a lack of appropriate characterization factors capable of reflecting the impacts of booster biocides on marine and terrestrial ecosystems. There are still many uncertainties relating to the environmental data associated with booster biocides, such as their environmental chemistry, fate and exposure patterns, toxicity, together with a lack of analytical methods for monitoring the occurrence, fate and toxicity of this type of biocides in the environment (Evans, Birchenough, and Brancato 2000; Yebra, Kiil, and Dam-Johansen 2004; Nikolaos Voulvoulis 2006). Moreover, the mix of booster biocides in paint varies from between paint applications, as the legislation regulating these chemicals changes over time, with an increasing number of countries prohibiting the marketing and use of certain booster biocides that others do not. Therefore, it is not currently possible to perform a quantitative assessment of the impact of booster biocides. But even if methods and characterization factors had been available, the associated inventory would be subject to high uncertainties due to the dynamic issues mentioned previously.

\section{Impact of copper emissions}

To assess the impact from copper that is emitted to coastal sea water during operation and hull cleaning, we used spatially differentiated ecotoxicity characterization factors for metals in coastal seawater. Copper emissions while sailing were modelled based on (Dong, Rosenbaum, and Hauschild 2016), where comparative toxicity potentials were developed for nine cationic metals ( $\mathrm{Cd}, \mathrm{Cr}(\mathrm{III}), \mathrm{Co}, \mathrm{Cu}(\mathrm{II}), \mathrm{Fe}(\mathrm{III}), \mathrm{Mn}$, $\mathrm{Ni}, \mathrm{Pb}$, and $\mathrm{Zn}$ ), in 64 Large Marine Ecosystems (LMEs) covering all coastal waters in the world. In particular, the marine copper ecotoxicity characterization factor for the LME CCF(LME) was employed. Based on daily 
reports from the vessels over a sampling period of two years, a discrete probability density function for the $L M E, P S(L M E)$, was constructed that shows how probable is it for a tanker vessel to sail within the area of a specific Large Marine Ecosystem (LME). The contribution to the marine ecotoxicological impact potential while sailing was calculated from equation (1):

Contribution to the marine ecotoxicological impact potential while sailing

$$
\begin{aligned}
& =\sum_{i=1}^{64} P S\left(L M E_{i}\right) * C C F\left(L M E_{i}\right) * \text { copper emission rate } \\
& * \text { duration of paint life cycle }
\end{aligned}
$$

Vessels sail close to coastal areas most of the time, so the model was considered adequate despite the fact that certain trade routes were not fully covered by the model (e.g. transatlantic voyages). The work in (Dong, Rosenbaum, and Hauschild 2016) was used to model the emissions due to paint removal during hull cleaning. Based on the location and the relative frequency of hull cleanings, the probability of cleaning at the $L M E, P C(L M E)$, was assessed. The probability density functions used for sailing and conducting a hull cleaning in a particular area are shown in the world map of figure 4 . The contribution to the marine ecotoxicological impact potential from hull cleanings was thus calculated in equation (2):

Contribution to marine ecotoxicological impact potential from hull cleanings

$$
\begin{aligned}
& =\sum_{i=1}^{64} \text { Number of hull cleanings throughout the paint life cycle } * P C\left(L M E_{i}\right) \\
& * C C F\left(L M E_{i}\right) * \text { amount of copper discharged during hull cleaning }(2)
\end{aligned}
$$

Copper emissions during hull cleanings avoid emissions that would occur during repainting at the end of the five-year lifecycle of the paint. Based on the location and the relative frequency of dry dockings, the probability of cleaning at a specific $L M E, P D(L M E)$, was assessed. Emissions to the marine environment 
were again based on (Dong, Rosenbaum, and Hauschild 2016), and the contribution to marine ecotoxicological impact potential from paint removal is shown in equation (3):

Contribution to marine ecotoxicological impact potential from paint removal

$$
=\sum_{i=1}^{64} P D\left(L M E_{i}\right) * C C F\left(L M E_{i}\right)
$$

* amount of copper emitted to the marine environment during paint removal (3)

From equations (1-3) we can derive the total marine ecotoxicological impact. In case of emissions to the soil, the contribution to the terrestrial ecotoxicological impact potential was based on (Owsianiak et al. 2013). When removing the paint from ship, copper is recycled to produce copper sulphide as mentioned before. This recycled material results in avoided copper sulphide production. We calculated the avoided toxicity and $\mathrm{CO}_{2}$ emissions from the avoided production. It is less than $0.1 \%$ of the emissions in our studied system. Therefore, we excluded this process in our calculation due to cut-off principle.

Lastly, all ecotoxicity impacts were converted from midpoint impact scores, (Potentially Affected Fraction of species (PAF)* $\mathrm{m}^{3} *$ day) into endpoint impact scores by multiplying with species density factors (species/ $\mathrm{m}^{3}$ ). As no characterization models have been identified from midpoint to endpoint for ecotoxicity, (Hauschild et al. 2013) we chose instead to weight the damage to freshwater, marine and terrestrial systems on the basis of the total number of species, a method similar to the endpoint characterization factor described in (Goedkoop et al. 2009, p.10). 


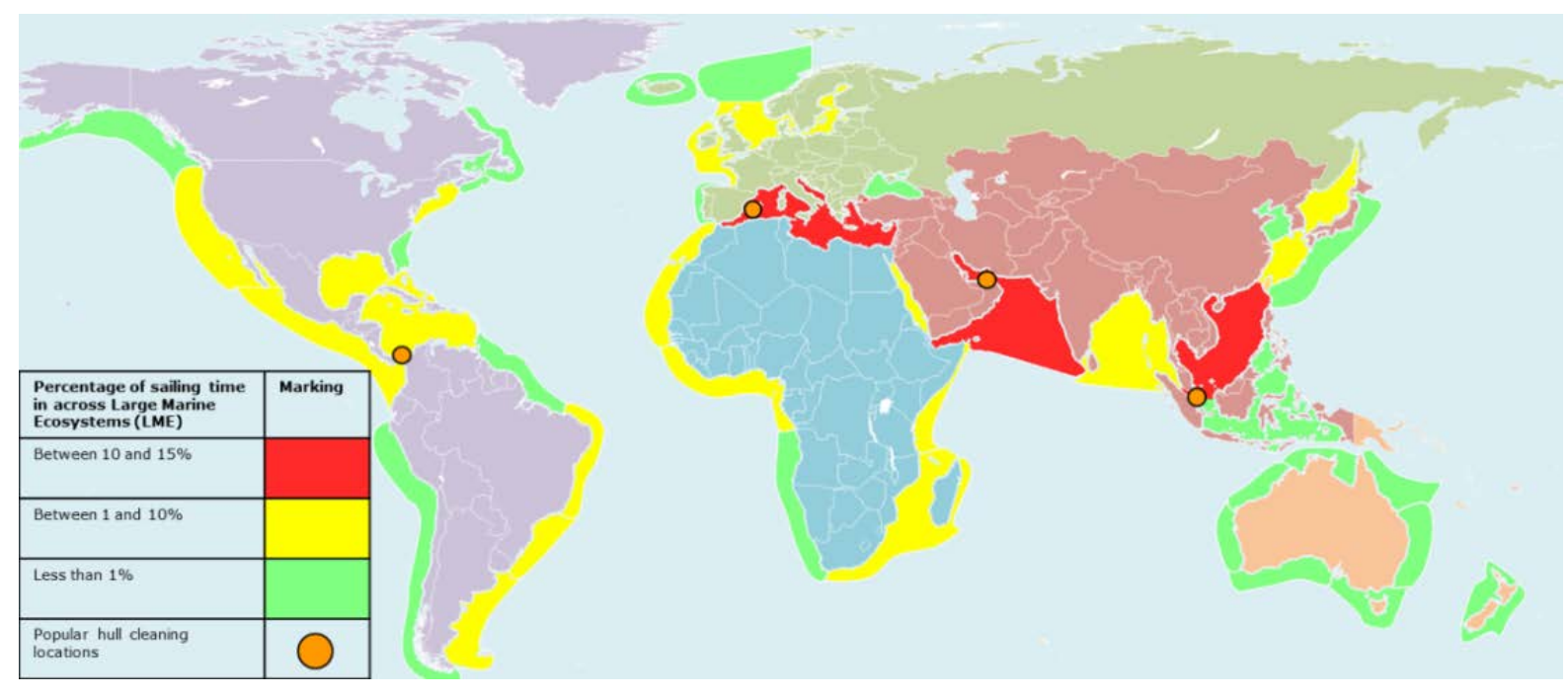

Figure 4: Sailing profile \& hull cleaning locations. Original map from (BVisual 2013)

\section{Extra fuel consumption due to fouling}

An important part of the analysis was to determine the development of fouling throughout the five-year life cycle of the paint, in order to assess how hull cleanings affect fuel efficiency. Over the past years, stakeholders from the shipping industry have established the ISO 19030 standard (ISO 2015) that calculates hull and propeller performance based on logged speed and shaft power measurements. Estimation of fuel consumption based on power monitoring often has so much scatter that it is impossible to conclude anything directly from speed power diagrams (Munk, Kane, and Yebra 2009). Moreover, to determine the effect of fouling on fuel consumption, the results need to be corrected for other sources of variance such as the propeller, machinery, water temperature, and sea state, in order to determine the effect of the changes in hull coating conditions over time (Lindholdt et al. 2015).

In practice, visual inspection is always conducted before cleaning, in order to assess the degree and severity of fouling. During visual inspection a team of divers assesses and documents the type of fouling as well as its extent. This happens in order to assess whether a hull cleaning is necessary and determine the cost for the cleaning service. Our study builds on these observations to assess how fouling develops over the life cycle of the paint. Specifically, a regression model was constructed based on the type of fouling organism 
that was observed, as well as the degree of fouling on the hull at the time of the inspection. Afterwards, the power penalty was estimated based on predictions of the change in total resistance for a range of representative coating and fouling conditions described in (Schultz, 2007, p. 338, Table II). The analysis covered a total of 47 vessel years, uniformly distributed throughout the 5 years of the paint lifecycle. Data were collected for a total of 20 vessels, each sailing for 2.4 years on average. The time the hull has been in the water has an important influence on the results. The fouling process occurs in stages, meaning that the hull is first settled by organic molecules, followed by bacteria, microalgae and protozoa and finally marine organisms such as algae, crustaceans \& slime (Yebra, Kiil, and Dam-Johansen 2004; Almeida, Diamantino, and de Sousa 2007). And the longer the vessel has been in the water since the last hull cleaning (or dry docking), the heavier the fouling. To correct for the effect of time, we calculated what we refer to as the fouling intensity (figure 5a, equation (4)), thus evaluating at what rate the power penalty increases at a specific point in the life cycle of the paint:

$$
\text { Fouling Intensity }=\frac{\text { Power penalty }}{\text { Time since last hull cleaning }}(4)
$$

Lastly a power transform was applied to correct for heteroscedasticity in the data, after which a linear regression model was fitted to the data as shown in Figure 5b. The accumulated fuel consumption was calculated by means of integration over the time period, where hull cleanings were modelled as discontinuities that reduced power penalty to zero at the time of occurrence. The model reveals three main periods in the lifecycle of the antifouling paint, the existence of which was further verified upon comparison with comments and observations available in the hull cleaning reports and discussions with experts. For the first two years (section $i$ of the graph in figure $5 b$ ) the paint system is successful in preventing fouling. Hull cleanings are not required, but even when they happen the degree of fouling is limited. Between two and three and a half years after application (section ii of the graph in figure $5 b$ ), the situation changes. Fouling begins to accumulate, and hull cleanings are necessary to restore performance. Lastly, after three and a half years (section iii of the graph in figure $5 b$ ) the antifouling paint is 'dead', 
meaning that fouling develops at a higher rate as active compounds in paint have been reduced and a thick leached layer prevents the diffusion of biocides (Yebra, Kiil, and Dam-Johansen 2004). Several diving reports highlighted the need for hull cleanings, in order to remove the thick leached layer and 'revitalise' the paint.
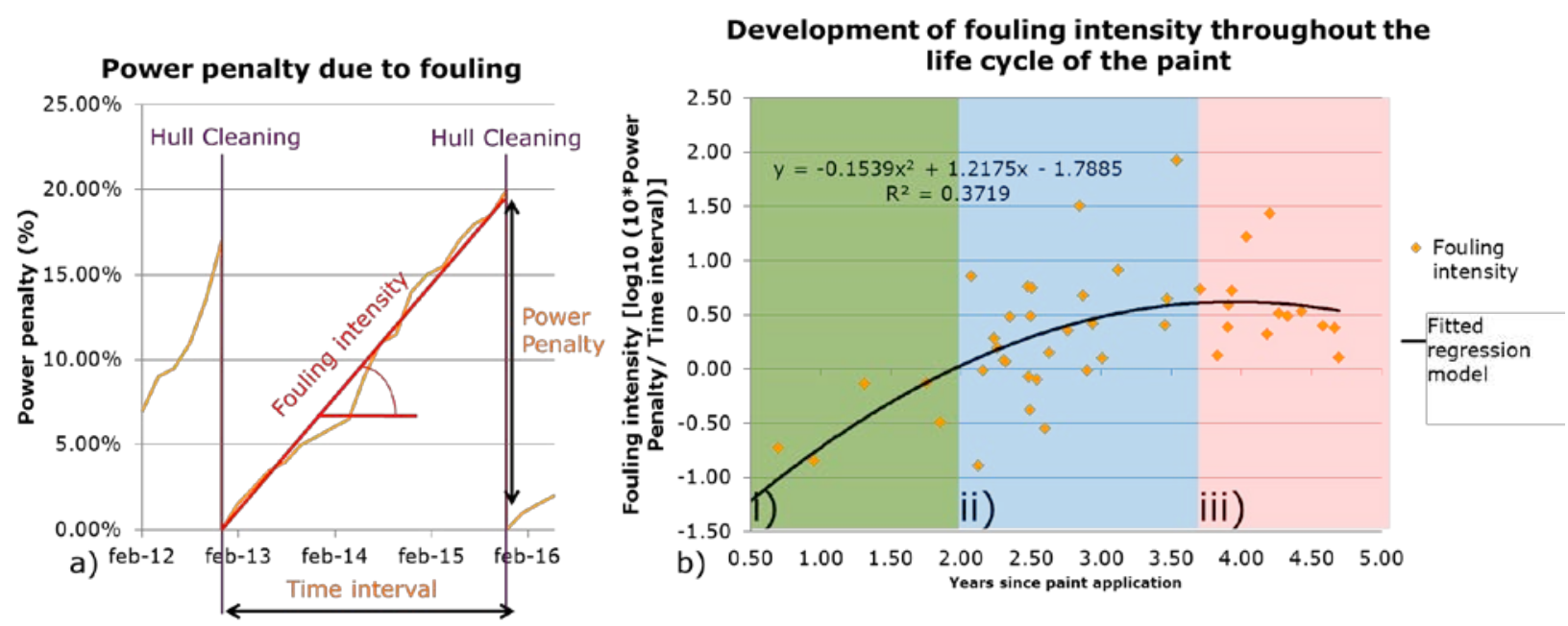

Figure 5: a) Conceptual model for fouling intensity b) Actual results throughout the paint lifecycle

It should be noted that the type and severity of fouling differs between different areas of the ship. Owing to the lack of sunlight, fouling is less extensive in the flat bottom of the vessel compared to the vertical sides. At the same time however, the flat bottom is far more likely to attract hard fouling (see an example of hard fouling in figure 1a).

\section{Direct and upstream environmental impacts from the hull cleaning service}

To determine the indirect emissions stemming from the provision of the hull cleaning service, including the employed equipment, we used a hybrid Environmental Input /Output (EIO) approach. As process based LCAs fail at addressing services sufficiently (Lenzen 2001), use of EIO is advocated for use in services as a prominent method to avoid critical cut offs (Kjaer et al. 2016). On the other hand input-output data for a product system such as the hull cleaning equipment that shares only a very small and atypical portion of an industry's output may exhibit significantly lower data quality (Suh et al. 2004). Our EIO analysis was based 
on the FORWAST database (FORWAST 2014; Kjaer et al. 2015), which is mass balanced, thus also covering the end of life phase of employed equipment.

For the direct emissions from fuel combustion, we used specific emission factors for marine fuels, as described in (Kjær et al. 2015), where FORWAST was again used to determine avoided indirect emissions stemming from fuel production. Our inventory included both emissions from avoided fuel consumption of the tanker vessel, but also the induced emissions from the hull cleaning service. Lastly reduced fuel consumption results in avoided emissions of toxic substances, the ecotoxicological impact of which on freshwater ecosystems was calculated using USEtox (Rosenbaum et al. 2008).

\section{Results and interpretation}

For discrete events (e.g. type of waste treatment) and cases where probabilities could not be determined, we used scenario analysis to determine a 3-point estimate, including High, Low, and Average scenarios, as described in Table S2 in the supplementary information. For the remaining parameters Monte Carlo analysis was employed to assess the sensitivity of the results to the change of these parameters. Figure 6 compares the different hull management schemes, and shows the effect of increasing hull cleaning frequency on costs and environmental impacts, as well as their uncertainty. In figure $6 a$, the results for the average scenario are shown. Scores are normalized against the score for the case where one hull cleaning is conducted as part of the hull management scheme. Figures $6 \mathrm{~b}, 6 \mathrm{c}$ and $6 \mathrm{~d}$ show the absolute scores for the three categories, with the shaded areas indicating the associated confidence intervals. The actual results can be found at Table S3 in the supplementary information. 


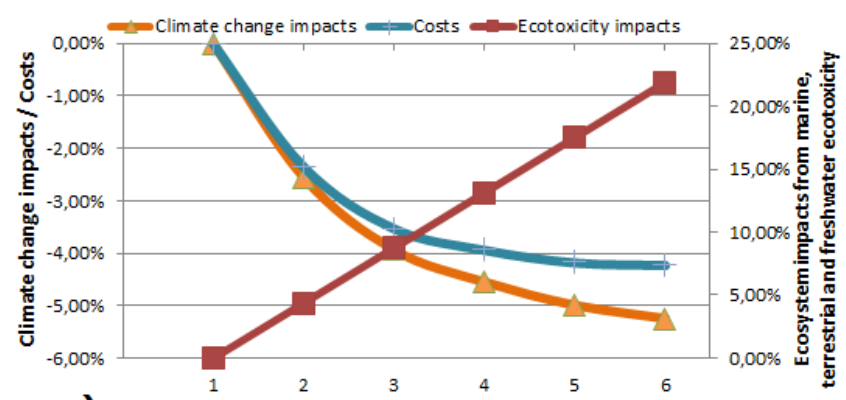

a) Number of hull cleanings within the hull management scheme

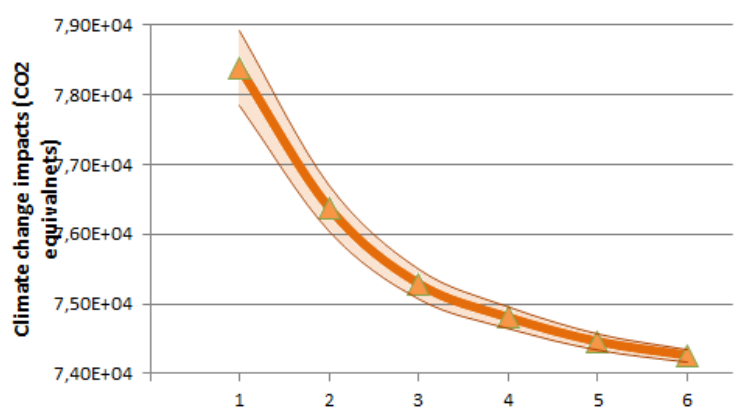

C) Number of hull cleanings within the hull management scheme

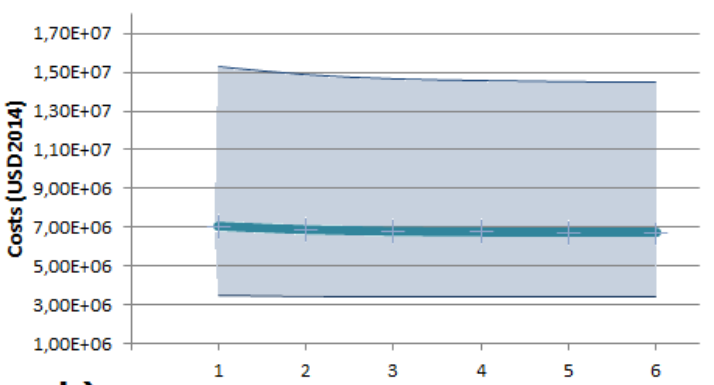

b) Number of hull cleanings within the hull management scheme
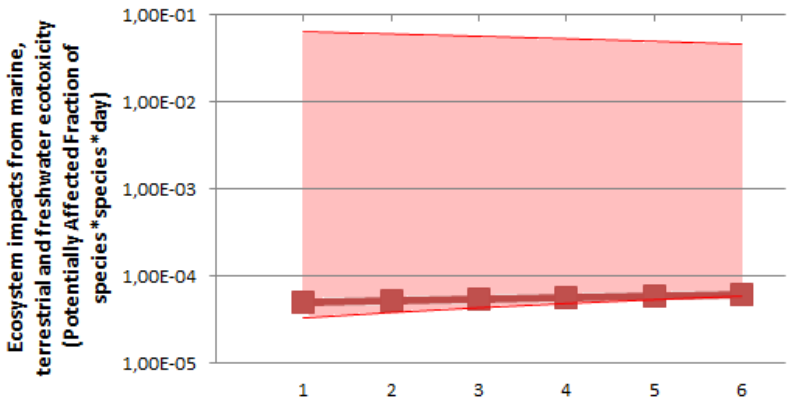

d) Number of hull cleanings within the hull management scheme

Figure 6: a) Normalized scores for the identified impact categories, as a function of the frequency of hull cleanings within the five year life cycle in regards to the functional unit for the average scenario. Scores are normalized against the score for one hull cleaning b) Cost as a function of hull cleaning frequency and associated confidence intervals c) Emissions of $\mathrm{CO}_{2}$ equivalents as a function of hull cleaning frequency and associated confidence intervals d) Ecotoxicity impacts as a function of hull cleaning frequency and associated confidence intervals. Notice that the results are plotted in logarithmic scale

In terms of costs, there appears to be a convex relationship between costs and hull cleaning frequency. While hull cleanings are likely to result in fuel savings, the service itself is characterized by diminishing returns, meaning that the more often a vessel is cleaned the less extra savings can be achieved. It is also shown that in case of low fuel prices and frequent hull cleanings, the costs are likely to outweigh the savings. In regards to climate change, increasing the frequency of hull cleanings is also likely to have a positive effect. Although extra emission savings diminish with increasing frequency, they still outweigh the limited impacts from the cleaning service itself. It should be noted that although both costs and climate change are driven by fuel consumption, costs vary much more due to the volatility in fuel prices, as shown in figures $6 \mathrm{~b}$ and $6 \mathrm{c}$ by the confidence interval.

Ecotoxicity impacts are characterized by high uncertainty - up to 3 orders of magnitude (figure $6 \mathrm{~d}$ ). The main source of uncertainty is the hull treatment during dry dock. In the negative and less probable scenario where the hull is sandblasted, the removed paint may end up in the soil. In this case shifting copper 
emissions during paint removal to the marine environment is likely to lead to decreased ecotoxicity impacts, mainly because marine species density is five orders of magnitude lower than terrestrial species (Goedkoop et al. 2009, p.11). In regards to the marine ecotoxicological impact potential, the impact from copper emissions depends on the coastal area where they are emitted -with up to three orders of magnitude difference across LMEs. The sailing profile for the tanker vessels under study contributes rather negatively in that regard, as the vessels under study mostly sail and receive hull cleanings in closed or semiclosed sea bodies such as the Mediterranean or South China sea, where water replenishment is slow and heavy metals have a higher seawater residence time (Dong, Rosenbaum, and Hauschild 2016). This leads to a higher characterization factor, which turn results in higher toxicity. Lastly, fuel savings translate to reduced toxic emissions, which in turn result in decreased impacts to freshwater ecotoxicity. These impacts however, appear to have a negligible effect on the results.

\section{Discussion and conclusions}

Hull management schemes can have a moderate fuel saving potential thereby justifying frequent cleanings - especially towards the end of the five-year dry docking cycle when the performance of the antifouling paint is weakened. Thus, they can result in decreased costs and reduced greenhouse gas emissions. At the same time however, ecosystem impacts from marine, terrestrial and freshwater ecotoxicity are likely to increase from hull cleanings, although this finding is subject to high uncertainty. Owing to their significant economic impact and the unclear regulatory framework, the operation of hull management systems is driven by commercial, rather than environmental, considerations. The study's recommendations are compatible to the regulatory framework that does not explicitly prohibit hull cleanings, and in some cases even seems to encourage them. At the same time though, regulatory inconsistencies across different maritime jurisdictions together with shipping economics mean that hull cleanings are conducted in specific ports. If combined with poor water circulation (i.e. long residence time of the water body), an extensive 
number of hull cleanings in a small geographical area could result in high copper concentrations in the water body (see (Valkirs et al. 2003, p.778) for a more detailed description in San Diego Bay, California).

It should be pointed out that there are a number of considerations that were not covered or partially addressed in this study. In particular, the environmental impacts of invasive species \& booster biocides in the antifouling paint are not covered by the assessment. Given the global operating profile of merchant vessels, assessment of environmental impacts of invasive species from hull management schemes is likely to be challenging. Firstly, it is important to determine whether hull cleanings have a positive or negative effect. Although hull cleanings do not result in mortality of all organisms (Woods et al. 2005), frequent and gentle cleaning of the hull is likely to prevent fouling (Tribou and Swain 2015). Although not standard practice yet, the introduction of novel technologies that collect waste during cleaning (Australian Government 2012, p.14) could mitigate the risk of introducing invasive species. Also, it is important to isolate the effect of hull management schemes since invasive species can be introduced into new areas through multiple pathways and vectors (Hanafiah et al. 2013). Booster biocides are characterized by high uncertainties -both in terms of their inventory and release rates to the environment (Erich and Baukh 2016)- while characterization factors -if they exist- need to be applied with caution (Hauschild et al. 2013). We have seen that hull cleanings shift copper emissions to soil during paint removal to the marine environment during sailing, and the environmental impacts from copper depend on the type of hull treatment during dry dock. If the same logic applies to the booster biocides, then booster biocides are likely to contribute in a similar manner to an already uncertain result. Future work could assess the impact of booster biocides taking into account the variability from weather conditions (Erich and Baukh 2016), the chemical composition of the different antifouling paints and technologies (Lindholdt et al. 2015) and their impact in different harbors and water bodies (Pla-Tolós et al. 2016).

An important element of hull management schemes is the timing of hull cleanings. Fouling is far more likely to develop when the vessel is idle for long periods, or sailing in warm waters. The effects of these 
phenomena are not explicitly taken into consideration. Moreover, the antifouling paint under study is currently considered a market average product. In the past few years new technologies have been developed such as Silyl Acrylate polymer technologies (Jotun 2016) and fouling control with hydro gel micro layer (Hempel 2016). So it is likely that these new technologies will deliver better protection from fouling and require fewer hull cleanings.

This study is a departure from the product focus seen in most LCAs, as the focus is on evaluating the effect of an intangible activity. We have experienced a number of challenges, some of which have already been discussed in LCA literature, while others invite for further work. Use of Hybrid Input /Output analysis is largely recommended when modelling services (Shrake, Bilec, and Landis 2013; Suh et al. 2004; Kjaer et al. 2015), otherwise there is a high risk of cut-off errors from omitted Scope 2 and Scope 3 emissions -which has been shown to exceed $75 \%$ of the carbon footprint in some service companies (Huang et al. 2009).

Furthermore, studies focusing on intangible activities, which do not result in ownership of a tangible asset, need to establish a connection between the avoided impacts in the life cycle of the reference system-in this study the tanker vessels'- and induced impacts from the activity. And that can be a complex task, as the activity is exposed to multiple uncertainties within the life cycle of the reference system. A specific aspect in the way the reference system operates can have a pronounced impact both on the demand and the economic and environmental impacts of the activity. This naturally questions whether the level of detail in the analysis captures the variations and developments in the operation of the reference system. That can be difficult to objectively measure and control. Lastly, quantifying intangible features such as service quality or service responsiveness can be challenging (an issue also discussed in the field of cost estimation by Huang et al (2012)). These features are hard to assess; but at the same time they are likely to affect the results considerably. 


\section{Acknowledgements}

The authors would like to thank the participating companies for the help and data provided and the TORM foundation for its financial support.

\section{References}

Almeida, E., T.C. Diamantino, and O. de Sousa. 2007. “Marine Paints: The Particular Case of Antifouling Paints." Progress in Organic Coatings 59 (1): 2-20. doi:10.1016/j.porgcoat.2007.01.017.

Armstrong, V.N. 2013. "Vessel Optimisation for Low Carbon Shipping." Ocean Engineering 73 (158): 195207.

Australian Government. 2012. Anti-Fouling and in-Water Cleaning Guidelines. Canberra.

BIMCO. 2013. "BIMCO Hull Fouling Clause for Time Charter Parties." https://www.bimco.org/Chartering/Clauses_and_Documents/Clauses/Hull_Fouling_Clause_for_Time _Charter_Parties.aspx.

Blanco-Davis, E., F. del Castillo, and P. Zhou. 2014. “Fouling Release Coating Application as an Environmentally Efficient Retrofit: A Case Study of a Ferry-Type Ship." International Journal of Life Cycle Assessment 19 (10): 1705-15. doi:10.1007/s11367-014-0780-8.

Blanco-Davis, E., and P. Zhou. 2014. "LCA as a Tool to Aid in the Selection of Retrofitting Alternatives." Ocean Engineering 77: 33-41. doi:10.1016/j.oceaneng.2013.12.010.

BVisual. 2013. "Visio Map of the World." http://blog.bvisual.net/2013/08/16/visio-map-of-the-world/.

Cao, S., J. Wang, H. Chen, and D. Chen. 2010. "Progress of Marine Biofouling and Antifouling Technologies." Chinese Science Bulletin 56 (7): 598-612. doi:10.1007/s11434-010-4158-4.

Chambers, L.D., K.R. Stokes, F.C. Walsh, and R.J.K. Wood. 2006. “Modern Approaches to Marine Antifouling Coatings." Surface and Coatings Technology 201 (6): 3642-52. doi:10.1016/j.surfcoat.2006.08.129. 
Choi, J.-Y., D.-S. Kim, and J.-Y. Lim. 2006. “Fundamental Features of Copper Ion Precipitation Using Sulfide as a Precipitant in a Wastewater System." Journal of Environmental Science and Health. Part A, Toxic/hazardous Substances \& Environmental Engineering 41 (6). Taylor \& Francis Group: 1155-72. doi:10.1080/10934520600623059.

Curran, M., L. De Baan, A.M. De Schryver, R. Van Zelm, S. Hellweg, T. Koellner, G. Sonnemann, and M.A.J. Huijbregts. 2011. "Toward Meaningful End Points of Biodiversity in Life Cycle Assessment." Environmental Science and Technology 45 (1): 70-79. doi:10.1021/es101444k.

Dong, Y., R.K. Rosenbaum, and M.Z. Hauschild. 2016. "Assessment of Metal Toxicity in Marine Ecosystems: Comparative Toxicity Potentials for Nine Cationic Metals in Coastal Seawater." Environmental Science \& Technology 50 (1): 269-78. doi:10.1021/acs.est.5b01625.

Earley, P.J., B.L. Swope, K. Barbeau, R. Bundy, J.A. McDonald, and I. Rivera-Duarte. 2014. "Life Cycle Contributions of Copper from Vessel Painting and Maintenance Activities." Biofouling 30 (1): 51-68. doi:10.1080/08927014.2013.841891.

Erich, S.J.F., and V. Baukh. 2016. “Modelling Biocide Release Based on Coating Properties." Progress in Organic Coatings 90 (January): 171-77. doi:10.1016/j.porgcoat.2015.10.009.

Evans, S.., A.. Birchenough, and M.. Brancato. 2000. "The TBT Ban: Out of the Frying Pan into the Fire?” Marine Pollution Bulletin 40 (3): 204-11. doi:10.1016/S0025-326X(99)00248-9.

Forster, P., V. Ramaswamy, P. Artaxo, T. Berntsen, R. Betts, D. Fahey, J. Haywood, et al. 2007. Changes in Atmospheric Constituents and in Radiative Forcing. Edited by Teruyuki Nakajima and Veerabhadran Ramanathan. Climate Change 2007: The Physical Science Basis. Cambridge, United Kingdom and NewYork, USA: Cambridge University Press.

FORWAST. 2014. "FORWAST." http://forwast.brgm.fr/. 
Fujairah port authority. 2016. "Safety / Security Regulations \& Requirements for Tankers Calling Fujairah (Oil Terminals \& Anchorage Area)." http://www.fujairahport.ae/files/148/ntm148.pdf.

Goedkoop, M., R. Heijungs, M. Huijbregts, A. De Schryver, J. Struijs, and R. Van Zelm. 2009. ReCiPe 2008: A Life Cycle Impact Assessment Method Which Comprises Harmonised Category Indicators at the Midpoint and the Endpoint Level.

Goldschmidt, A., and H.-J. Streitberger. 2003. BASF Handbook on Basics of Coating Technology.

Gratsos, G., and P. Zachariadis. 2005. Life Cycle Cost of Maintaining the Effectiveness of a Ship's Structure and Environmental Impact of Ship Design Parameters. RINA International Conference: Design and ....

Hanafiah, M.M., R.S.E.W. Leuven, N. Sommerwerk, K. Tockner, and M.A.J. Huijbregts. 2013. “Including the Introduction of Exotic Species in Life Cycle Impact Assessment: The Case of Inland Shipping." Environmental Science and Technology 47 (24): 13934-40. doi:10.1021/es403870z.

Hauschild, M.Z., M. Goedkoop, J. Guinée, R. Heijungs, M. Huijbregts, O. Jolliet, M. Margni, et al. 2013. “Identifying Best Existing Practice for Characterization Modeling in Life Cycle Impact Assessment." International Journal of Life Cycle Assessment 18 (3): 683-97. doi:10.1007/s11367-012-0489-5.

Hempel. 2016. "Hempaguard X7 89900 | Hempel.com."

http://www.hempel.com/en/products/hempaguard-x7-89900.

Huang, X.X., L.B. Newnes, and G.C. Parry. 2012. "The Adaptation of Product Cost Estimation Techniques to Estimate the Cost of Service." International Journal of Computer Integrated Manufacturing 25 (4-5). Taylor \& Francis: 417-31. doi:10.1080/0951192X.2011.596281.

Huang, Y.A., M. Lenzen, C. Weber, J. Murray, and H. Matthews. 2009. "The Role of Input-output Analysis for the Screening of Corporate Carbon Footprints." Economic Systems Research 21 (3): 217. doi:10.1080/09535310903541348. 
Inchcape. 2016. "Cape Town Frequently Asked Questions." http://issshipping.com/Microsites/AdditionalPages/Cape Town/Cape Town FAQs.html.

Interlux. 2012. Antifouling 101 A Comprehensive Guide from Interlux.

International. 2010. Antifouling Performance at the Level You Choose.

International Maritime Organization. 2003. "Guidelines for Inspection of Anti-Fouling Systems on Ships." Resolution MEPC.105(49), 1-8.

International Maritime Organisation. 2009. Guidance on Best Management Practices for Removal of AntiFouling Coatings from Ships, Including TBT Hull Paints. Circular $|L C-L P| 1 \mid 31$.

ISO. 2015. ISO/DIS 19030: Ships and Marine Technology - Measurement of Changes in Hull and Propeller Performance [under Development]. TC 8 Ships and Marine Technology.

Jotun. 2016. "SeaQuantum X200 - the Ultimate Fuel Saver | Jotun."

http://www.jotun.com/it/en/b2b/paintsandcoatings/products/SeaQuantum-X200.aspx.

Kiil, S., K. Dam-Johansen, C.E. Weinell, M.S. Pedersen, and S.A. Codolar. 2002. "Dynamic Simulations of a Self-Polishing Antifouling Paint Exposed to Seawater." Journal of Coatings Technology 74 (6): 45-54. doi:10.1007/BF02698368.

Kjaer, L.L., N.K. H??st-Madsen, J.H. Schmidt, and T.C. McAloone. 2015. “Application of Environmental InputOutput Analysis for Corporate and Product Environmental Footprints-Learnings from Three Cases." Sustainability 7 (9): 11438-61. doi:10.3390/su70911438.

Kjaer, L.L., A. Pagoropoulos, J.H. Schmidt, and T.C. McAloone. 2016. “Challenges When Evaluating Product/Service-Systems through Life Cycle Assessment." Journal of Cleaner Production, January. doi:10.1016/j.jclepro.2016.01.048. 
Kjær, L.L., A. Pagoropoulos, M. Hauschild, M. Birkved, J.H. Schmidt, and T.C. McAloone. 2015. “From LCC to LCA Using a Hybrid Input Output Model - A Maritime Case Study." In Procedia CIRP, edited by Sami Kara, 29:474-79. doi:10.1016/j.procir.2015.02.004.

Laurent, A., S.I. Olsen, and M.Z. Hauschild. 2012. "Limitations of Carbon Footprint as Indicator of Environmental Sustainability." Environmental Science \& Technology 46 (7). American Chemical Society: 4100-4108. doi:10.1021/es204163f.

Laurenti, R., D. Lazarevic, S. Poulikidou, V. Montrucchio, L. Bistagnino, and B. Frostell. 2014. “Group ModelBuilding to Identify Potential Sources of Environmental Impacts Outside the Scope of LCA Studies." Journal of Cleaner Production 72: 96-109. doi:10.1016/j.jclepro.2014.03.001.

Lenzen, M. 2001. “Errors in Conventional and Input-Output - Based Life-Cycle Inventories." Journal of Industrial Ecology 4 (4): 127-48. doi:10.1162/10881980052541981.

Lindholdt, A., K. Dam-Johansen, S.M. Olsen, D.M. Yebra, and S. Kiil. 2015. “Effects of Biofouling Development on Drag Forces of Hull Coatings for Ocean-Going Ships: A Review." Journal of Coatings Technology and Research 12 (3): 415-44.

Lunn, I. 1974. Antifouling: A Brief Introduction to the Origins and Development of the Marine Antifouling Industry.

Maritime and port authority of Singapore. 2008. "Underwater Diving Operations within the Port." http://www.mpa.gov.sg/sites/circulars_and_notices/pdfs/port_marine_circulars/pc08-05.pdf.

Maynes, R. 1998. "Speed and Consumption Disputes under English Law - UK P\&amp;I." UK P\&I Club. http://www.ukpandi.com/knowledge/article/speed-and-consumption-disputes-under-english-law$1917 /$.

Munk, T., D. Kane, and D. Yebra. 2009. "The Effects of Fouling and Corrosion on the Performance of Ocean- 
Going Vessels." In Advances in Marine Antifouling Coatings and Technologies, 148-76. Cambridge: Woodhead Publishing.

Oil Companies International Marine Forum. 2016. "Ship Inspection Report ( SIRE ) Programme, Vessel Inspection Questionnaires for Oil Tankers, Combination Carriers, Shuttle Tankers, Chemical Tankers and Gas Tankers." https://www.ocimf.org/media/58881/VIQ-2014-Rev-12-Final.pdf.

Owsianiak, M., R.K. Rosenbaum, M.A.J. Huijbregts, and M.Z. Hauschild. 2013. “Addressing Geographic Variability in the Comparative Toxicity Potential of Copper and Nickel in Soils." Environmental Science and Technology 47 (7): 3241-50. doi:10.1021/es3037324.

Pla-Tolós, J., P. Serra-Mora, L. Hakobyan, C. Molins-Legua, Y. Moliner-Martinez, and P. Campins-Falcó. 2016. “A Sustainable on-Line CapLC Method for Quantifying Antifouling Agents like Irgarol-1051 and Diuron in Water Samples: Estimation of the Carbon Footprint." Science of the Total Environment 569-570. Elsevier B.V.: 611-18. doi:10.1016/j.scitotenv.2016.06.181.

Rosenbaum, R.K., T.M. Bachmann, L.S. Gold, M.A.J. Huijbregts, O. Jolliet, R. Juraske, A. Koehler, et al. 2008. “USEtox - the UNEP-SETAC Toxicity Model: Recommended Characterisation Factors for Human Toxicity and Freshwater Ecotoxicity in Life Cycle Impact Assessment." The International Journal of Life Cycle Assessment 13 (7): 532-46. doi:10.1007/s11367-008-0038-4.

Ruiz, G.M., J.T. Carlton, E.D. Grosholz, and A.H. Hines. 1997. "Global Invasions of Marine and Estuarine Habitats by Non-Indigenous Species : Mechanisms, Extent, and Consequences." American Zoologist. doi:10.1093/icb/37.6.621.

Sartale, S.., and C.. Lokhande. 2000. "Growth of Copper Sulphide Thin Films by Successive lonic Layer Adsorption and Reaction (SILAR) Method." Materials Chemistry and Physics 65 (1): 63-67. doi:10.1016/S0254-0584(00)00207-8. 
Schiff, K., D. Diehl, and A. Valkirs. 2004. "Copper Emissions from Antifouling Paint on Recreational Vessels." Marine Pollution Bulletin 48 (3-4): 371-77. doi:10.1016/j.marpolbul.2003.08.016.

Schultz, M. 2007. "Effects of Coating Roughness and Biofouling on Ship Resistance and Powering." Biofouling 23 (5-6): 331-41. doi:10.1080/08927010701461974.

Schultz, M.P., J. a Bendick, E.R. Holm, and W.M. Hertel. 2011. “Economic Impact of Biofouling on a Naval Surface Ship." Biofouling 27 (1): 87-98. doi:10.1080/08927014.2010.542809.

Shrake, S.O., M.M. Bilec, and A.E. Landis. 2013. "The Application of a Multi-Faceted Approach for Evaluating and Improving the Life Cycle Environmental Performance of Service Industries." Journal of Cleaner Production 42 (March): 263-76. doi:10.1016/j.jclepro.2012.10.039.

Smith, T.W.P., J.P. Jalkanen, B.A. Anderson, J.J. Corbett, J. Faber, S.. Hanayama, E.. O'Keeffe, et al. 2014. Third IMO GHG Study 2014.

Suh, S., M. Lenzen, G.J. Treloar, H. Hondo, A. Horvath, G. Huppes, O. Jolliet, et al. 2004. "System Boundary Selection in Life-Cycle Inventories Using Hybrid Approaches." Environmental Science and Technology 38 (3): 657-64. doi:10.1021/es0263745.

The BAT group. 1996. Reduction of Emissions from Ship Yards. Nordic Council of Ministers.

The Danish Shipowners' Association. 2012. "Green Transport of Global Trade." https://www.shipowners.dk/.../5/green-transport-of-global-trade.pdf.

The Economist. 2015. "The Economist Explains: How to Stop Invasive Underwater Species." The Economist. http://www.economist.com/blogs/economist-explains/2015/05/economist-explains-35.

Tribou, M., and G. Swain. 2015. "Grooming Using Rotating Brushes as a Proactive Method to Control Ship Hull Fouling." Biofouling 31 (4). Taylor \& Francis: 309-19. doi:10.1080/08927014.2015.1041021. 
United Nations Conference on Trade and Development. 2013. Review of Maritime Transport 2013.

Valkirs, A.O., P.F. Seligman, E. Haslbeck, and J.S. Caso. 2003. “Measurement of Copper Release Rates from Antifouling Paint under Laboratory and in Situ Conditions: Implications for Loading Estimation to Marine Water Bodies." Marine Pollution Bulletin 46 (6): 763-79. doi:10.1016/\$0025-326X(03)00044-4.

Voulvoulis, N. 2006. "Antifouling Paint Booster Biocides: Occurrence and Partitioning in Water and Sediments." Handbook of Environmental Chemistry, Volume 5: Water Pollution 5 (PART O): 155-70. doi:10.1007/698-5-053.

Voulvoulis, N., M.D. Scrimshaw, and J.N. Lester. 1999. "Alternative Antifouling Biocides." Applied Organometallic Chemistry 13 (3): 135-43. doi:10.1002/(SICI)1099-0739(199903)13:3<135::AIDAOC831>3.0.CO;2-G.

Woods, C., O. Floerl, I. Fitridge, O. Johnston, K. Robinson, D. Rupp, N. Davey, N. Rush, and M. Smith. 2005. Efficacy of Hull Cleaning Operations in Containing Biological Material. Vol. 3.

Yebra, D.M., S. Kiil, and K. Dam-Johansen. 2004. “Antifouling Technology-past, Present and Future Steps towards Efficient and Environmentally Friendly Antifouling Coatings." Progress in Organic Coatings 50 (2): 75-104. doi:10.1016/j.porgcoat.2003.06.001.

Zielinska, B., J. Sagebiel, J.D. McDonald, K. Whitney, and D.R. Lawson. 2004. “Emission Rates and Comparative Chemical Composition from Selected in-Use Diesel and Gasoline-Fueled Vehicles." Journal of the Air \& Waste Management Association 54 (9): 1138-50. 